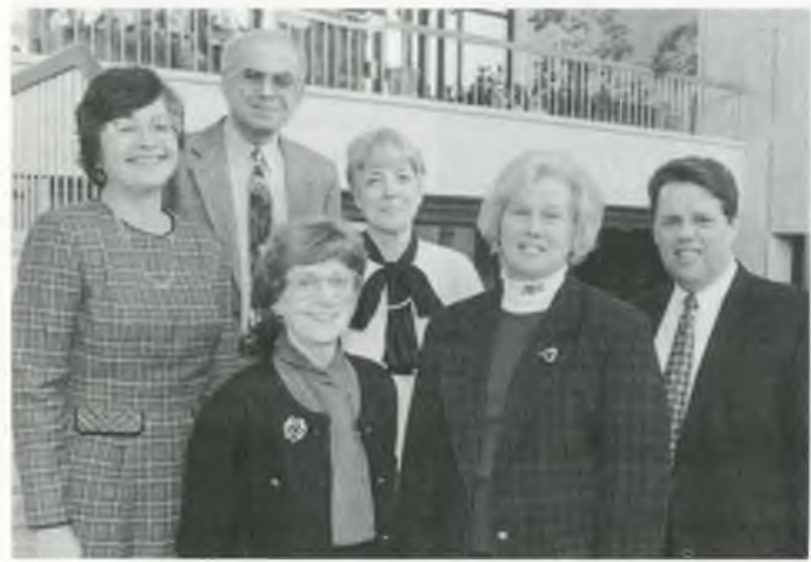

Directors of the libraries forming the new Chesapeake Information and Research Library Alliance are (1 to $\mathrm{r}$ ): Susan Martin, Mod Mekkawi, Ann MacLeod, Barbara Smith, Susan Bryteson, and James Neal.

Mason's innovation in undergraduate education), and our evolving role as part of the team of mentors students rely on as they work their way through college."

Take a virtual visit of the center at http:/ ulcweb.gmu.edu/communities/library/about.html.

\section{Alliance formed in Chesapeake Bay}

Six research institutions in the Chesapeake Bay region have formed the Chesapeake Information and Research Library Alliance (CIRLA). The founding members of CIRLA are the University of Delaware, Georgetown University, Howard
University, Johns Hopkins University, the University of Maryland at College Park, and the Smithsonian Institution, all members of the Association of Research Libraries. The following individuals were elected as officers: James Neal Johns Hopkins), president; Susan K. Martin (Georgetown), vice-president/president-elect; and Barbara Smith (Smithsonian), secretary-treasurer.

The overall goal of CIRLA is to enhance education and research at member institutions through collaborative development of library collection and service programs and expanded use of information technology.

\section{Compilers needed for new CLIP Notes}

ACRL's College Libraries Section's CLIP Notes Committee is seeking volunteers to compile CLIP Notes. The CLIP Notes (College Library Information Packets) series, in its 16 th year, provide data and sample documents from college and small university libraries on topics of interest to academic librarians.

The CLIP Notes committee wants your ideas for topics to cover. Recently and soon-to-bepublished CLIP Notes have investigated allocation formulas, patron surveys, reference train-

\title{
Library faculty workload: Implementation of a teaching faculty model
}

The issue of developing an appropriate model for library faculty workload has often been difficult and contentious at many universities. Western Illinois University (WIU) Libraries has addressed this concern in an approach that differs from the traditional structured clerical workweek. All campus faculty are issued workload guidelines that include both the traditional classroom as well as performance and activity classes (e.g., physical education, art and music studio instruction) that vary in size and preparation demands.

For both performance and activity classes, the usual model has been taken from the $\mathrm{Na}$ tional Association of Schools of Music which emphasizes a 2:3 ratio for private lessons, i.e., two hours of classroom instruction is equated with three hours of private instruction. At WIU this equals up to 18 assigned hours plus four office hours. This same model is also applied to the library faculty. As with teaching faculty, research and service requirements are conducted outside any teaching or primary duties assignment.

A more detailed explanation of this model is provided in ERIC (ED 385291). Other questions can be answered by writing to Frank Wm. Goudy at Western Illinois University, Macomb, IL 61455; (309) 298-2749._Frank Wm. Goudy, Western Illinois University 